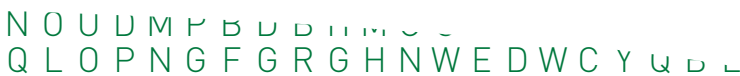

OFETZHNAXCFTJKJZMHZDHNBNU.

$\cup D A M O E \cup P Q L O P N G F G R G H N W E D W C Y Q \nvdash\llcorner$

A A E K JBVOOFETZHNAXCF T J K J Z M H Z D N B ,

A M M T T M T GNTZUARNH I O G D O I PR G M D S A U r

EKTNUGW E T L U J CK I O P M E SWLNCAWZYKFE Q L O, $M O D C O S V N E S O P Q O M G D N V U S G R V L G R A K G E C L Z E M S$.

$T N J Y|J Q T A H| N|N G R E E O Y A Z T E F N A X J R C N| F Z K M$,

DCKPELOIMSEBVCSEY LVVHNVUAJKUVXESYM,

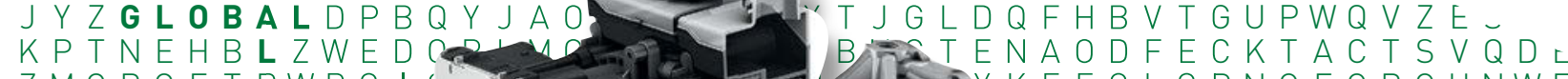
ZMCROETRWP O I The TKFEQLOPNGFGRGHNWE

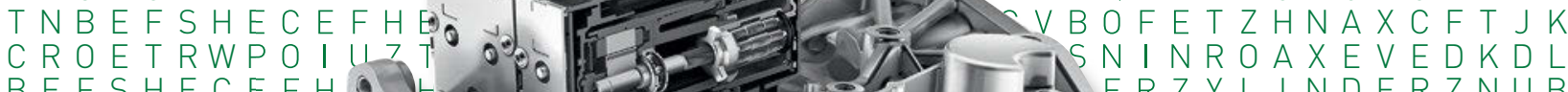
BEFSHECEFH L SOBPIOSGBZ WA SEDCKLPSXWEW $F E|W R E Q R| U$ I CWDAYWTRDY mmmmis ID B I H J J M I KOQA $P J M F I J H L M$
$C G T V D G L E M$ $J T Z G E T O$ I VWM C RW U U A KDPJKPSL LS J T D S Y K J EK J R C K O I J $M O T Y Q O G N T$ T N U E I N R L U D C O O V C E S O $\begin{array}{lllllllll}J & Y & \mid & Z & Q & Y & A & H & \text { I } \\ N & J & K & V & N & J & R & A & K\end{array}$ $A A O O U A N D O N$ $U D M B B D B H M G R$
$A A O E U A N D O N G$ I $M O T M Q O G N T Z D S Q O N$

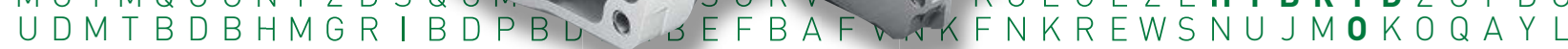
FEI DREQR I UZTREWQLKJHGFDSAMMBVCXYMLMHKNUNEQTFCX CIMNSTRECLPQACEZRWDXAYHBMWRZIRFVEGBJEUHBZGWRZV $P J M N|J H L M O K N| J U H B Z G V T F C R D X E S N W A S R E C G M H T I L Q N V X D$ C GTJDGLETUOADGJLYCBMWRZIPSFHKTVNZLMOIJEUHBZGWR J T Z UETOIZRWQETUOMBCYNVXADGJLKHESYSCBFGMHTILQNV 


\title{
Double Clutch Systems
}

\author{
Modular and highly efficient \\ for the powertrain of tomorrow
}

Matthias Zink
Uwe Wagner
Clement Feltz

D v

$J \mathrm{ZMH}_{L}$

$A G Q S W \mid\llcorner\ldots$

F I MBCHSEH

I C E C B S T P O I O D C V ז

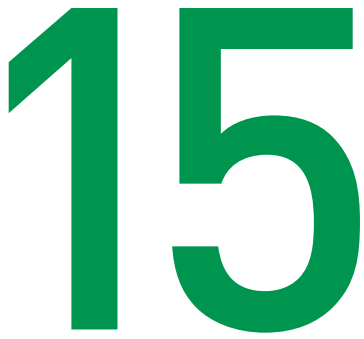

$D G \vee T Q U J X R E L K J H G F D S A|V| \ldots$

YLMRTXAGYWPHCEQA YWS XEE CK,

$C X V N H O U B I J B Z G V T F C R D X E S N W A S K\llcorner$

Z VTFLUJADGYCBMWRZIPSFHKTVNZLMU.

$X D B P O R U T E T M B C Y N V X A D G J L K H E S Y S C B M B \iota$

DCSKUPOWRWZTWHNEDKUNWPONCALVIKZTWHIV

EHKLPFLKJKO I UZTREWQYXCVBNMIQWUOIUZTR

WDXAYHASGSVNPIZRWQSCGZNJ|MNSTRVNPIZRWQ_

I L Z UKOGIKCKPMNESWLNCXWZYKFEDIOPPMNESWLNCX

$R \cup C Z G Z M Q G O D N V U S G R V L G R V K G E C E Z E M D N V U S G R V L G h$ QATSLOKZINEXOMNYAZTEWNFX JLRN I FEXOMNYAZTEW ICLOMEPSCVCYI I FAMUAN J Y $\cap \cdots$

KMN S R D O

L I E P N N

B S A T B

$P \mid$ E P P

$R \cup C Z$

B S A

D G V

$Y\llcorner\wedge$

$C X$

Z V

$X D$ $S Q F H B Q F G O B R E L N F X T J C$ I ZPMFDRO I D F G KLDF $\because A \cup K Z Q H|O G D N O| E R N$ L REWSPDLRB EFBAFVNK $L K Z Q H|O G D N O| E R N G N$ Z EMDNVUSGRVLGRVK NSPDLRB E F A F V N K F $M O L K J H G F D S A M M B V$ B ZPHCEQA YWSXEE C $\cong V B Z G V T F C R D X E S N$ 10 Y C B MWR Z I P S H K

$B M B C Y N \vee X A D G J L K$ K Z TWH NE D K NWPr

POWRWZTWHNEDKUNWPONCA

$F L K J K O \mid U Z T R E W Q Y X C \vee B N M$ HASESVNPIZRWQSCGZNJ|M

GIKCKPMNESWLNCXWZYKFF

I A S U S V N P I Z RWQSCGZN J I

I KCKPMNESWLNCXWZYKF

' OXODNVUSGRVLGRVKG

1 I NEXOMNYAZTEWNF

' $C Y L J N E W C L V \vee F H$.

$\cap N \vee \cup S G R \vee L G F$ 


\section{Introduction}

Alongside the established stepped automatic transmission and CVT, the double clutch transmission in particular has achieved considerable market penetration in the last few years (Figure 1).

Significant growth has been seen in the European and Chinese markets in particular, and current forecasts indicate that in ten years' time, every fifth automatic transmission will be a double clutch transmission.

The following basic requirements apply to automatic transmissions in accordance with current definitions:

- Maximum comfort achieved through powershift capabilities combined with a dynamic driving experience

- Ideal spreading and the highest possible level of efficiency across all oper-ation modes

- Actuating mechanism operated with minimal losses and, where possible, without the need for additional effort while the combustion engine is turned off

- Hybrid function presented in the simplest and most flexible manner possible

A double clutch transmission, which fulfils all of these requirements, including an integrated hybrid function, entered into series production in Japan at the end of 2013 under the name "i-DCD". Figure 2 shows the dry double clutch transmission and the wet version for the application "SH-AWD", as well as the parts supplied by Schaeffler, which are both modular and highly efficient!

In addition to using highly efficient, hydrostatically operated double clutches (equipped with a concentric slave cylinder, or "CSC"), a newly developed actuator with an integrated control unit is also used in these applications (a hydrostatic clutch actuator, or "HCA"), and a gear actuator featuring an "active interlock" concept. Thanks to the "power-on-demand" actuator elements present in this design, it is possible to reduce the NEDC power consumption levels for transmission and clutch operation to values lower than $20 \mathrm{~W}$.

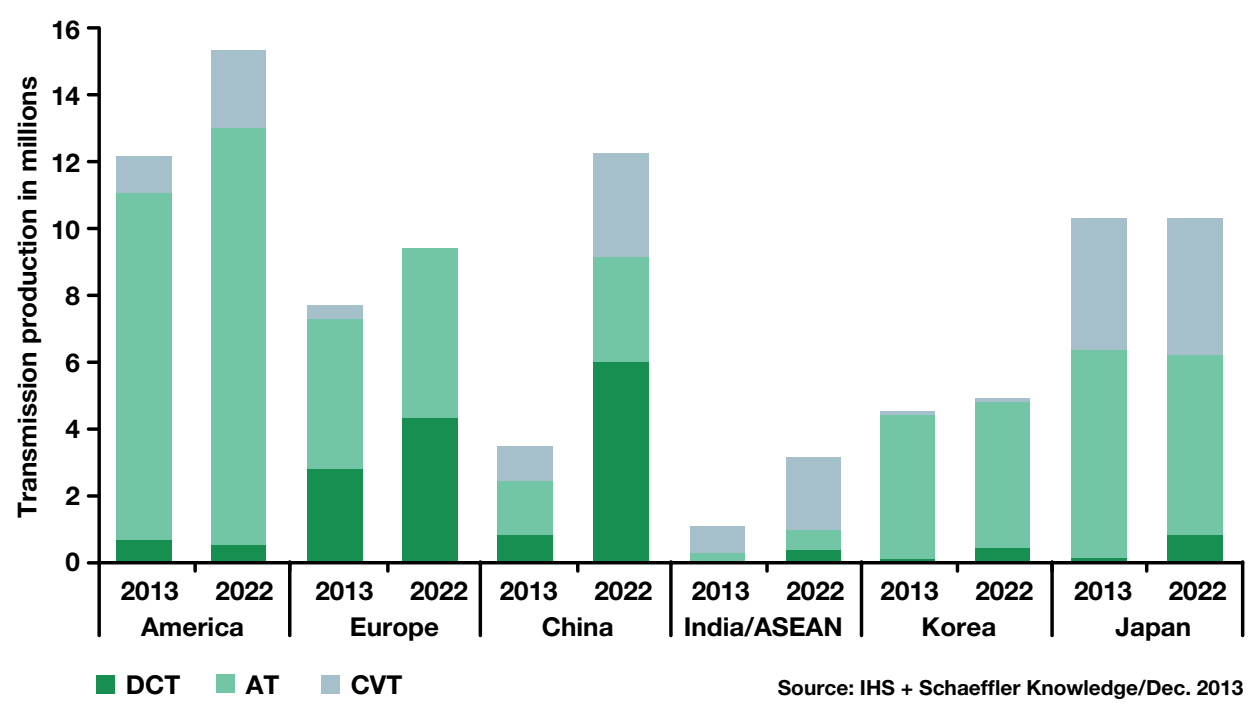

Figure 1 Production volumes for different automatic transmissions (selected regions) 


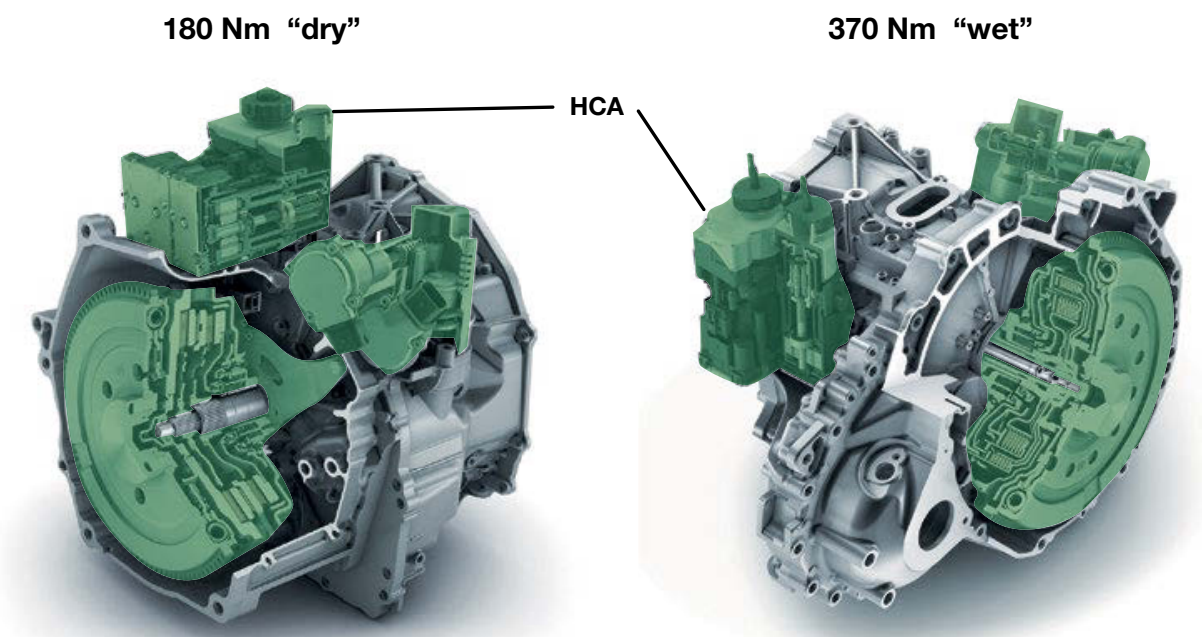

Parts supplied by Schaeffler

Figure 2 Dry double clutch transmission "i-DCD", wet double clutch transmission for "SH-AWD"

\section{The double clutch:}

\section{"dry or wet" or "dry and wet"?}

As was previously the case, comfort when driving off and shifting gear remains a key focus for the double clutch system - with regard to driving off in particular, there exists a strong, established and extremely vigilant competitor when it comes to the $\mathrm{NVH}$, comfort and dynamics of the torque converter. In this respect, the new, highly innovative design of the iTC torque converter [1] in particular will see double clutch systems face a new challenge across all disciplines.

Back in 2006, a chapter was dedicated to the question of "dry or wet?" as part of the LuK Symposium, and following on from a large number of series production projects (Figure 3) that have since been carried out, it has become apparent that the clutch technology used for the corresponding applications is determined on the basis of the technical rationale for the specific clutch load described at the time.
In terms of efficiency, the dry double clutch continues to be the first choice, wherever the torque capacity permits this. Combined with electromechanical actuating mechanisms, the dry double clutch represents a system solution that sets a benchmark for efficiency. In addition, this version of the double clutch places few requirements on the peripheral equipment of the transmission, as no additional oil cooling is required for the clutch. As a result, implementation is achieved with greater ease and with a tendency towards increased cost-effectiveness.

However, this clutch variant also poses specific challenges. Cooling is achieved by means of air convection, meaning frictional heat needs to be stored temporarily in the pressure plates, which increases weight and inertia levels. Furthermore, the ability to control dry clutches tends to be more critical than for wet systems. Clutches with wear adjustment mechanisms in particular are more difficult to control due to the more complex mechanics of the internal structure, but also due to the greater variance of the friction coefficients of the dry linings in general. A dry friction system must be fully 


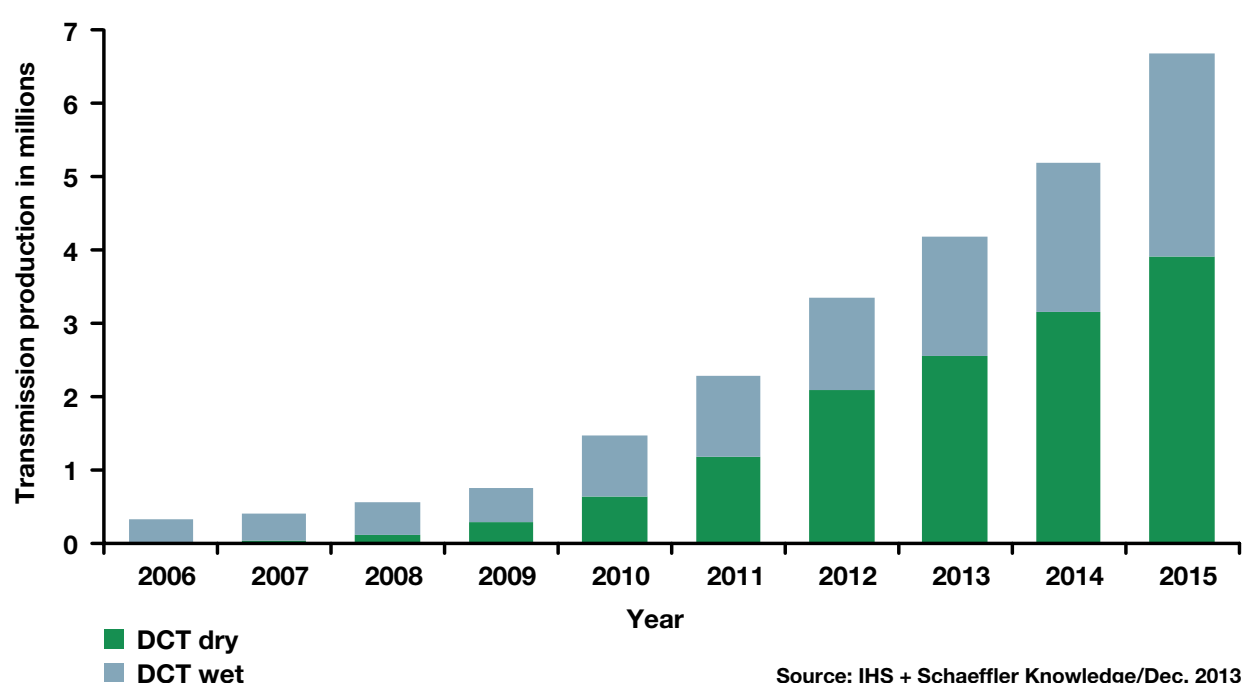

Figure 3 Production volumes for different double clutch transmissions

functional throughout the entire life of the clutch; oil changes - and therefore the addition of fresh additives, such as for a wet clutch - is not necessary or possible for a dry clutch.

The primary development objectives are to reduce inertia levels and, in particular, to enhance controllability and thus optimize the comfort characteristics of the dry double clutch when driving off and shifting gear. Reducing internal friction and compensating the geometric torsional vibration excitation using a new design featuring direct actuation (DCC), the optimization of the accuracy of the individual parts, new friction linings with significantly improved damping and actuators with special control algorithms to control juddering (anti-judder control system) will also considerably improve the comfort characteristics. These measures are explained in detail in [2].

For applications with higher specific clutch loads, wet double clutch systems are generally used, as this oil-cooled version has the advantage of a higher cooling capacity in comparison with the dry version.
On current applications, the transition from dry to wet occurs at driving torques of between 250 and $350 \mathrm{Nm}$. In addition, the wet double clutch is also smaller and lighter in terms of its transmission capacity. To date, this version has also featured a more simple mechanical arrangement, as it does not require a fixture for wear adjustment.

However, today's wet clutch systems cannot fully utilise the benefits of reduced weight and inertia, as they require additional masses in the damper system to achieve the necessary level of torsional vibration isolation. In addition, the oil cooling system, which has a positive effect on performance, together with the peripheral equipment required for oil cooling, also represents a considerable additional effort with respect to design and energy, which has a negative effect on weight, cost and efficiency.

At the very least, optimised wet double clutch systems should therefore be capable of utilising the lower inertia levels owing to an appropriately powerful damping system. Furthermore, attention should be paid to improving efficiency by reducing drag 
losses and using a highly efficient actuating mechanism.

In comparison with dry double clutches, future wet clutch systems should also include design elements to reduce geometric excitation, as well as optimised linings and dynamic actuator systems with the option of an "anti-judder control system" [3] in response to the increased challenges facing modern powertrains in relation to $\mathrm{NVH}$.

\section{The actuating mechanism}

From a functional viewpoint, the key requirement placed on the actuating mechanism of double clutch transmissions is most certainly the need to combine adequate dynamics and performance with the highest levels of efficiency. Actuators therefore not only require a minimum amount of energy to operate the clutch and transmission, but should, for example, also be capable of supporting the aforementioned anti-judder control system.

A modern actuator system should therefore only use power when required ("power on demand"). Furthermore, it must also be possible to operate the actuator system when the combustion engine is not running, in order to support start-stop and hybrid functions. For these operating states, special attention must be paid to noise gener-ation, as the masking noises of the combustion engine are not present in this instance. In terms of design, the actuating mechanism should take up as little space as possible, and a modular design may be beneficial in order to reduce the costs for different applications.

Forward-thinking ideas for expanding the functions of such modular actuator systems, while reducing their level of complexity at the same time, are detailed in [4].

\section{Outlook/transition}

Double clutch transmissions have all the prerequisites and real potential for becoming the basic architecture for the powertrain of tomorrow. The i-DCD transmission, produced in series since 2013, is a trendsetting example of a modular, highly efficient and even integrated hybridised double clutch transmission.

The consistent use and inclusion of hybrid elements in the design - for example, for driving off using electric power - will further strengthen the position of the double clutch transmission in relation to alternative transmission concepts from competitors.

\section{Literature}

[1] Lindemann, P.; Steinberger, M.; Krause, T., iTC - innovative torque converter solutions paving the way to the future. $10^{\text {th }}$ Schaeffler Symposium, 2014

[2] Kimmig, K.-L.: The highest levels of comfort: The dry double clutch rises to the challenge. $10^{\text {th }}$ Schaeffler Symposium, 2014

[3] Englisch, A.; Goetz, A.; Baumgartner, A.; Endler, T.; Lauinger, C.; Steinmetz, S.: The wet double clutch: Thinking in systems. $10^{\text {th }}$ Schaeffler Symposium, 2014

[4] Mueller, B.; Rathke, G.; Grethel, M.; Man, L.: Gearshift actuation: Less complexity, more functionality. 10 $0^{\text {th }}$ Schaeffler Symposium, 2014

Open Access. This chapter is distributed under the terms of the Creative Commons Attribution Noncommercial License, which permits any noncommercial use, distribution, and reproduction in any medium, provided the original author(s) and source are credited. 